ADLFI. Archéologie de la France -

INFORMATIONS

Informations

une revue Gallia

Midi-Pyrénées | 2013

\title{
Plateau du Larzac
}

Mehdi Dhaou

URL : http://journals.openedition.org/adlfi/17247

ISSN : 2114-0502

Éditeur

Ministère de la culture

Référence électronique

Mehdi Dhaou, «Plateau du Larzac », ADLFI. Archéologie de la France - Informations [En ligne], Midi-

Pyrénées, mis en ligne le 03 mai 2016, consulté le 02 mai 2019. URL : http://journals.openedition.org/ adlfi/17247

Ce document a été généré automatiquement le 2 mai 2019.

(c) Ministère de la Culture et de la Communication, CNRS 


\title{
Plateau du Larzac
}

\author{
Mehdi Dhaou
}

Lien Atlas (MCC) :

1 Dans le cadre de notre Master 2 à propos des systèmes de circulation sur la partie nord du causse du Larzac, nous avons effectué une opération de prospection inventaire le long d'anciens chemins repérés par une approche archéogéographique (études de cartes et cadastres anciens, recherche des anomalies dans le paysage, analyse spatiale et lecture d'image aériennes et satellites etc.)

2 La forte humidité malgré la saison estivale a entraîné un regain de la végétation rendant la visibilité très difficile, aussi les conditions climatiques assez rigoureuses ont fortement limité notre vitesse d'investigation. Toutefois, nous avons pu repérer trois espaces dont la concentration de matériel permet d'envisager la présence de sites archéologiques pour les périodes qui nous concernaient. Nous notons aussi la présence en nombre de zones de concentrations de matériel en céramique vernissée, nous les avons répertoriées mais pas analysées puisque celles-ci n'entrent pas dans notre problématique et ne font pas partie de notre champ d'expertise.

3 Parmi les potentiels sites que nous avons répertoriés, le premier est déjà connu et une partie du mobilier céramique en a déjà été étudiée (parcelle 959, commune de Millau, coordonnées Lambert 93, X: 709498.71; Y: 6331335.78), le propriétaire des lieux a souhaité le conserver. La richesse de cet espace fait penser à A. Vernhet (CAG12) et à la possible présence d'une occupation de type villa dans le secteur. Le second site potentiel est plus isolé et situé au sud du lieu-dit la Buissière, dans la parcelle 74 (commune de Millau, coordonnées Lambert 93, X: 708432.93 ; Y : 6327010.53). Ici nous avons repéré de nombreuses céramiques communes, notamment de l'amphore, ainsi que de la TCA et de nombreux résidus ferreux (scories). La forte dégradation du mobilier retrouvé limite la datation du site, même s'il semble que la potentielle occupation soit antique.

Le dernier espace de concentration de mobilier se situe au sud de la ferme de Combebren dans la parcelle 32 (commune de Millau, coordonnées en Lambert 93, X: 714808.07; Y : 
632887416.16). Le mobilier retrouvé se situe sur un massif de pierres qui semble être le résultat de l'épierrement mécanique d'un champ situé dans une dépression à proximité. Il nous semble donc que le mobilier présent ait subi la même opération et serait donc originaire au moins partiellement de ce champ.

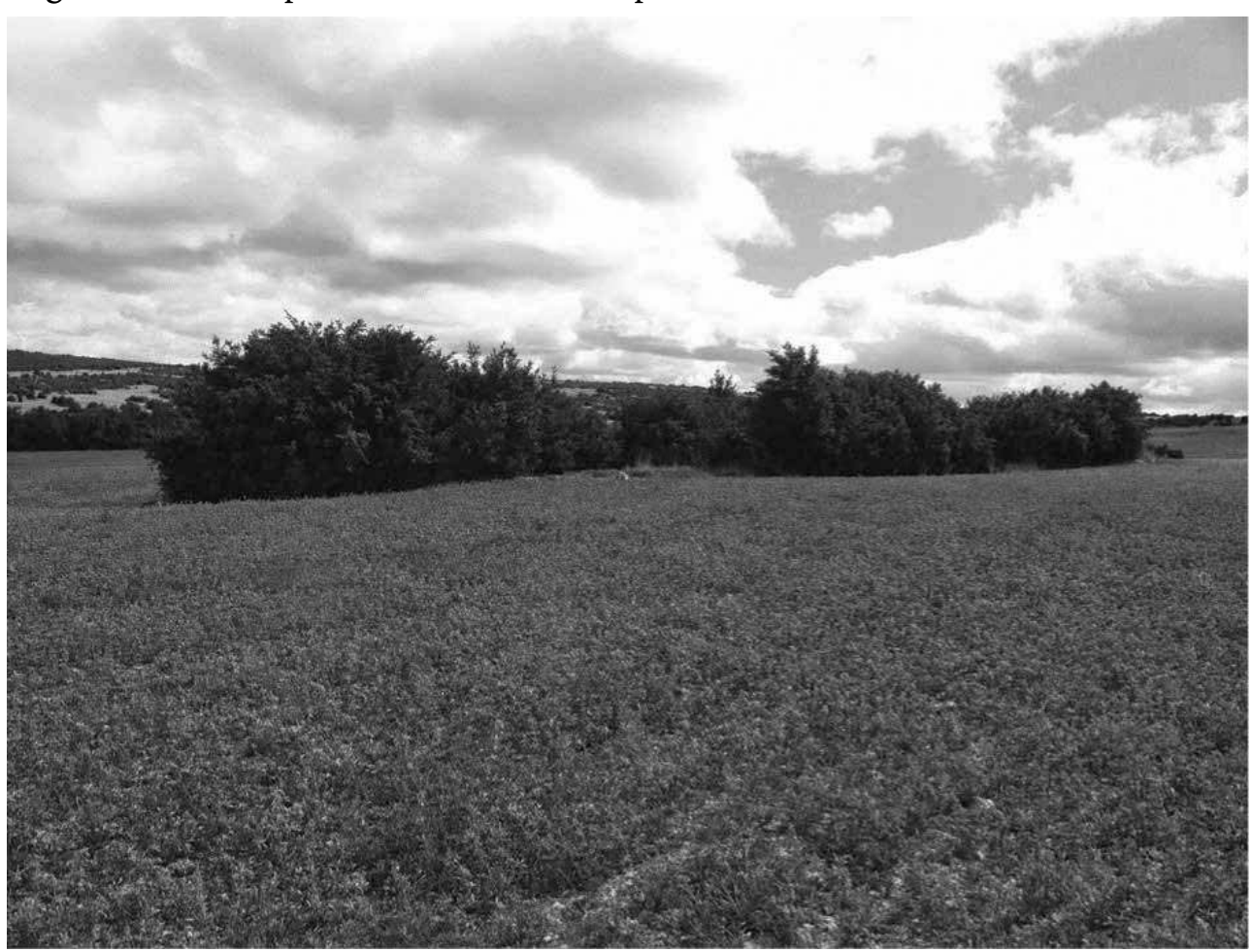

Fig 01

Vue générale depuis le chemin du premier site repéré au sud de La Blaquière.

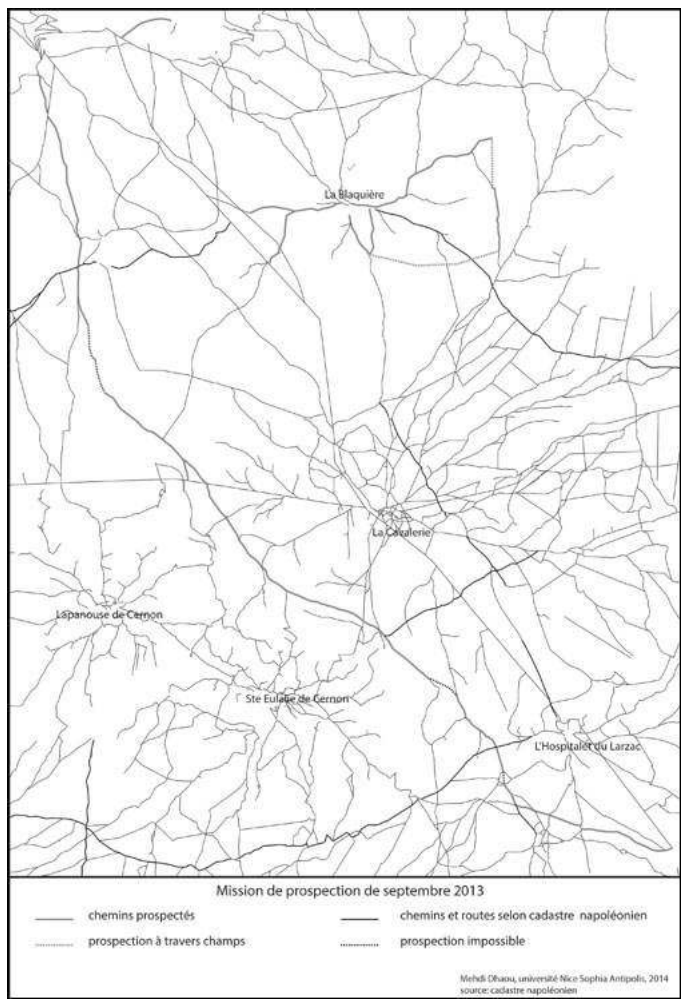


Fig 02

Zone prospectée

5 Nous avons aussi repéré un enclos de pierre bien conservé avec des moellons grossièrement taillés, d'un diamètre de 10 à $12 \mathrm{~m}$ (parcelle 105, commune de Millau coordonnées Lambert 93, X: 706684.44; Y: 6330996.28). Si nous n'avons pas trouvé d'élément de datation pour cette construction, sa position sur la limite entre les communes de Millau et de Creissels (tout comme pour l'essentiel des structures mégalithiques de cette partie du causse) est intéressante pour comprendre la structuration de l'espace.

6 Les éléments découverts lors de la prospection (concentrations de mobilier) et l'analyse du paysage nous ont permis d'étudier assez précisément la résilience des voies de circulation sur le plateau ainsi que leur conservation dans le paysage actuel. Aussi, si l'occupation à proximité des chemins repérés semble attestée durant l'Antiquité et la période Moderne, nous n'avons pas trouvé de traces d'occupations médiévales malgré la présence certaine de sites datant de cette période (CAG 12). Il semble donc que les réseaux viaires ont évolué entre la fin de l'Antiquité et le Moyen Âge pour répondre à de nouvelles formes et problématiques de circulation.

\section{INDEX}

Index géographique : Midi-Pyrénées, Aveyron (12)

operation Prospection inventaire (PI)

Mots-clés : céramique, scories, enclos, voirie

\section{AUTEURS}

MEHDI DHAOU

CNRS 